\title{
The role of nurses in diet-related chronic diseases- future perspectives
}

\author{
Fatjona Kamberi ${ }^{1}$, Rezarta Lalo ${ }^{2}$
}

1 University of Vlore "Ismail Qemali", Research Center for Public Health, Vlore, Albania. 2University of Vlore "Ismail Qemali", Department of Health Care, Vlore, Albania.

Diet-related chronic diseases, such as diabetes mellitus, hypertension, cardiovascular and renal diseases affected millions of individuals, resulting in diseaserelated complications such as stroke and heart attack. Evidence strongly supports the fact that multiple dietary factors influence this diseases and the modification of diet can have powerful, beneficial effects in prevention and management but in most cases, the modification of diet results after the disease is installed. Because of their interaction with patients, the nurse's role in preventive care includes observing the many factors that contribute to chronic conditions. The aim was to assess the patients with chronic diseases regarding their diet before - after the installation of the diseases. The study took place in Vlore Regional Hospital Albania, Pathology ward in May 2018, duration two weeks. The sample was composed of 12 patients. The study data collected by a questionnaire which includes general and nutritional information. The Body Mass Index (BMI) was calculated in the base of the patient's height and weight. Mean age 67.25 years, $S D \pm 5.64$.
Most prevalent diseases were diabetes mellitus (25\%), hypertension (25\%), cardiovascular and renal diseases (35\%), hepatic cirrhosis (8.33\%). $50 \%$ of patients were overweight BMI interval [25.00-29.99] and $17 \%$ were obese in the I category, BMI interval [35.0-40.00]. All patients reported that their diets changed after hospitalization. Diets modifications included no consumption of fats, salt and to quit smoking and alcohol consumption.

Results suggest that prevention is crucial in the treatment of the chronic conditions and nurse's role is vital in helping patients by educating them on risks and promoting healthy lifestyles.
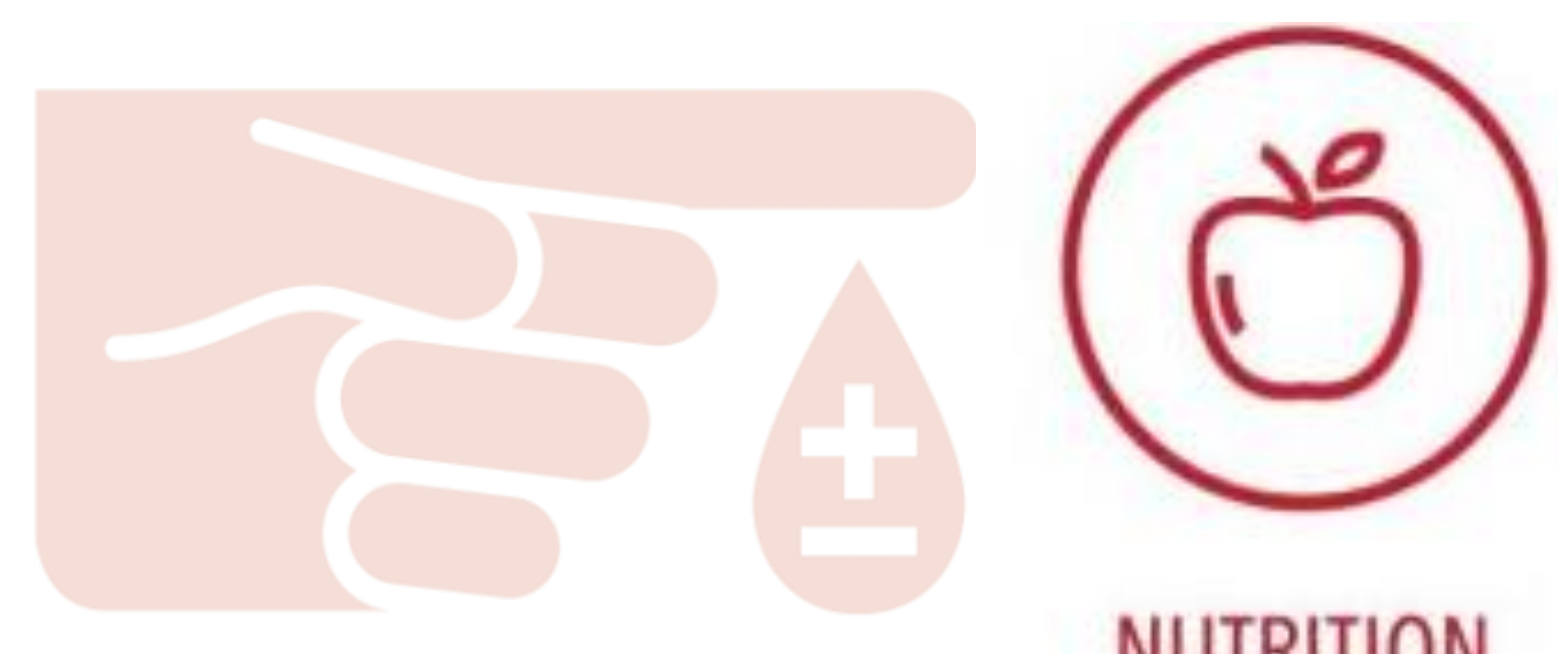

NUTRITION

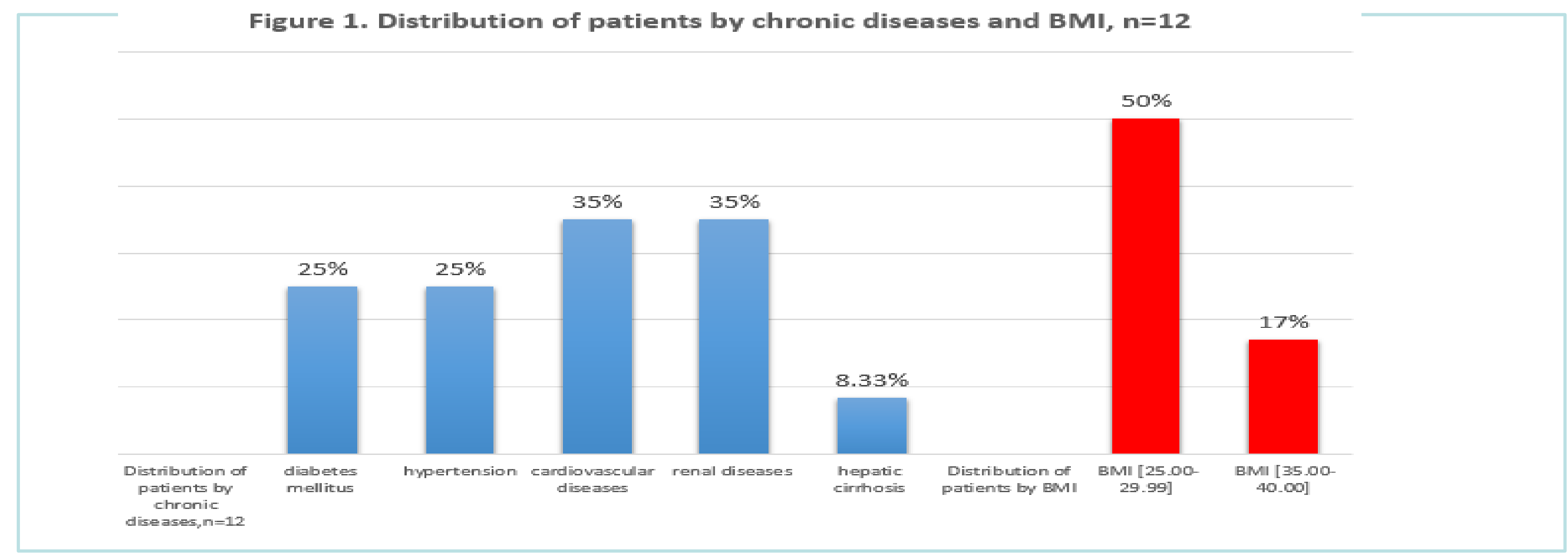

References

- Xiaoyue Xu, Deborah Parker, Caleb Ferguson \& Louise Hickman (2017) Where is the nurse in nutritional care?, Contemporary Nurse, 53:3, 267-270

- Victoria Vaughan Dickson,Robyn A. Clark,Eneida Rejane Rabelo-Silva,Harleah G. Buck. (2013). Self-Care and Chronic Disease. Nursing Research and Practice Volume 2013, Article ID 827409, 2 pages Vivien Coates (2017). Role of nurses in supporting patients to self-manage chronic conditions. Nursing Standard. 17 May 2017 / Vol 31 issue 38 .

Bodenheimer, T., MacGregor, K., \& Stothart, N. (2005). Nurses as leaders in chronic care. BMJ (Clinical research ed.), 330(7492), 612-3.

- Canadian Nurses Association (2005). Chronic diseases and Nursing. A summary of issues. Available on https://www.cna-aiic.ca/ /media/cna/page-content/pdf-en/bg3_chronic_disease_and_nursing_e.pdf 